\title{
Responsabilidade do Estado por Erro Jurisdicional
}

ORESTES LISBOA ALVES DO NASCIMENTO FILHO Aluno da FA7, orientado pela profa. Cynara Monteiro Mariano. oresteslisboa@hotmail.com

Sumário: 1. Introdução. 2. Fases de evolução da responsabilidade civil do Estado. 3. A responsabilidade do Estado no atual ordenamento jurídico brasileiro. 4. Responsabilidade civil do Estado por atos jurisdicionais. 5. Considerações finais. 6. Referências bibliográficas.

Resumo: Este trabalho examina a controversa questão da Responsabilidade do Estado por erro praticado em uma de suas funções: a jurisdicional. Onde demonstraremos a possibilidade de atribuição de responsabilidade objetiva ao Estado e subjetiva ao agente causador do dano (Juiz). O estudo é baseado em uma pesquisa documental, pois trata-se de um exame da doutrina e jurisprudência. Observamos a forma particular como a teoria da Responsabilidade do Estado evoluiu diante da necessidade de proteção dos particulares. Fizemos ainda uma consideração sobre a referida teoria no atual ordenamento jurídico brasileiro e sobre a necessidade de sua aplicação nos casos de erros judiciais. Além disso, analisamos a viabilidade da aplicação da responsabilidade pessoal do juiz. Concluímos afirmando a admissibilidade, tanto da responsabilidade do Estado por atos judiciais, quanto à responsabilidade pessoal do Juiz.

Palavras-chave: Responsabilidade. Estado. Jurisdição. Erro. Juiz.

\section{@ INTRODUÇÃO}

A Constituição Federal vigente, em seu art. 37, §6 $6^{\circ}$ atribui ao Estado a responsabilidade objetiva pelos danos que seus agentes, nessa condição, causarem a terceiros. Porém, temos visto que a doutrina e a jurisprudência vacilam em aplicar esta regra a todo e qualquer agente público. 
Neste trabalho examinamos a controversa questão da responsabilidade do Estado por erro praticado em uma de suas funções: a jurisdicional. Tentaremos demonstrar, num primeiro momento, a admissibilidade de atribuição de responsabilidade objetiva ao Estado e, num segundo momento, a possibilidade da responsabilidade pessoal do agente causador do dano (juiz).

\section{co FASES DE EVOLUÇÃo DA RESPONSABILIDADE CIVIL DO ESTADO}

A responsabilidade civil do Estado esteve por muito tempo limitada pelo conceito de irresponsabilidade, porém, diante da dinâmica social, evolveu para o conceito de responsabilidade com culpa, ou responsabilidade civilística e, finalmente, para o de responsabilidade pública (Meirelles, 1994, p. 555). Veja-se:

1. Quando não era aceita qualquer forma de atribuição de responsabilidade ao Estado e, portanto, predominava a teoria da irresponsabilidade;

2. Quando a atribuição da responsabilidade passa a ser aceita vinculada à idéia de culpa do agente, e, portanto, predominava a teoria civilista;

3. Quando a atribuição da responsabilidade passa a ser aceita desvinculada da idéia de culpa e, portanto, predominavam as teorias publicistas.

\subsection{TEORIA DA IRRESPONSABILIDADE}

No período do estado absolutista, a teoria da irresponsabilidade era predominante e consagrava a autoridade estatal como infalível, incontestável e superior aos súditos, tanto que se veiculavam máximas, como, por exemplo, "The king can do no wrong” e "Le roi ne peut mal faire” (em vernáculo: O rei não pode errar).

Os partidários desta teoria sustentavam a infalibilidade real e, conseqüentemente, a impossibilidade do Estado reparar qualquer dano que porventura causasse, posto que a atribuição de responsabilidade ao Estado "significaria colocá-lo no mesmo nível que o súdito, em desrespeito à sua soberania” (Di Pietro, 2005, p. 563).

A teoria da irresponsabilidade resistiu aos ataques liberais por muitos anos, sendo gradualmente suprimida, até que sucumbiu completamente no decorrer do século XX.

\subsection{Teoria Civilista}

A teoria civilista deve ser compreendida como uma teoria de transição da era da irresponsabilidade para a era da responsabilidade, pois, ao compreender que o rei não pode ser confundido com o Estado, contraria a teoria da irresponsabilidade, e, ao admitir a atribuição de responsabilidade ao Estado, permite o surgimento das teorias publicistas.

Segundo a teoria civilista, o rei, detentor exclusivo da prática de atos de império, não poderia ser responsabilizado pela prática dos referidos atos, pois, 
segundo a supramencionada máxima inglesa "The king can do no wrong”, o monarca era infalível e seus atos eram revestidos de prerrogativas e privilégios inerentes, e eram regidos por um Direito especial, que exorbitava o Direito comum.

Já o Estado, através de seus prepostos, praticava atos de gestão, cujo escopo era a gestão do serviço público e a administração do patrimônio público. O Estado somente poderia ser responsabilizado por estes atos, pois, ao praticá-los, colocavase em posição de igualdade com os particulares, submetendo-se, inclusive, ao regime jurídico de Direito Privado.

Mas, em face da reconhecida dificuldade, senão impossibilidade, de enquadrar como atos de gestão todos os atos praticados pelo Estado na administração do patrimônio público e na prestação de seus serviços, a distinção entre os atos de império e os atos de gestão foi abandonada. Não obstante o repúdio à distinção entre mencionados atos, muitos autores continuaram a afirmar que o Estado será responsável sempre que sua culpa for demonstrada, subsistindo, portanto, a teoria da responsabilidade civil subjetiva do Estado (Di Pietro, 2005, p. 564).

Porém, como foi dito anteriormente, esta teoria (da responsabilidade civil subjetiva do Estado) é um ponto de transição entre a teoria da irresponsabilidade do Estado e a teoria da responsabilidade objetiva do Estado, tendo, portanto, a doutrina da responsabilidade civil subjetiva perdido espaço para a teoria da responsabilidade civil objetiva do Estado, que, como veremos a seguir, veicula a idéia de que o Estado será civilmente responsabilizado sem a necessidade de comprovação de culpa.

\subsection{Teorias Publicistas}

Como apontamos, em face da teoria civilista, o Estado, quando acionado judicialmente a reparar um dano, submetia-se ao mesmo regime dos particulares, ou seja, a vítima, além de ter sofrido o dano provocado pelo Estado, deveria demonstrar em juízo a sua culpa.

Porém, no século XIX, o desenvolvimento industrial originou um surto de progresso, fato que ocasionou a multiplicação de danos, e, por conseguinte, evidenciou a hipossuficiência das vítimas e a necessidade de conferir-lhes maior proteção.

O célebre caso Blanco, ocorrido na França em 1873, constitui-se marco inicial da teoria publicista, em decorrência da comoção social gerada pelo acidente de Agnès Blanco, que foi atropelada por uma vagonete da Companhia Nacional de Manufatura do Tabaco, sendo o primeiro passo no sentido de conferir autonomia de Direito Público à matéria da responsabilização estatal. No caso em tela, o pai da menina Blanco promoveu ação civil de indenização, fundamentando-se no princípio da responsabilidade civil do Estado por prejuízos causados a terceiros, em decorrência de ação danosa de seus agentes, fato que gerou um conflito de competência entre a jurisdição comum e o contencioso administrativo. Suscitada a controvérsia, o Tribunal de Conflitos decidiu que o Tribunal Administrativo 
processaria e julgaria o caso, e não o Tribunal Judiciário Comum. A conseqüência dessa decisão é o reconhecimento da aplicação das normas de Direito Público, e não das de Direito Civil, em casos de responsabilidade do Estado.

A partir dessa decisão, começam a surgir as teorias publicistas da responsabilidade do Estado por atos dos seus agentes.

A primeira teoria publicista é a da culpa do serviço, também chamada de culpa administrativa, ou teoria do acidente administrativo, cujo preceito maior asseverava que a responsabilidade do Estado surge da culpa do serviço, e não da idéia de culpa do funcionário.

Segundo essa teoria, a culpa do serviço público ocorrerá quando o serviço público funcionar mal, não funcionar (hipótese de omissão) ou funcionar atrasado. Ocorrendo qualquer uma dessas hipóteses, restará configurado o acidente administrativo (culpa administrativa ou culpa do serviço) e, conseqüentemente, a responsabilidade do Estado, que não dependerá de perquirição de culpa do funcionário.

Portanto, na teoria do acidente administrativo a culpa é dicotômica, pois de um lado há a culpa individual do funcionário, pela qual ele próprio responde e, de outro, a culpa anônima do serviço público, pela qual o Estado responde, já que, nesse caso, diante da impossibilidade de identificação do agente público causador do dano, presume-se que o serviço público funcionou mal.

A segunda teoria é a do risco, uma evolução da anterior, pois nela o elemento culpa é substituído pelo elemento nexo de causalidade, ou seja, existindo nexo de causalidade entre o funcionamento do serviço público e o prejuízo sofrido pelo administrado, o fato do serviço público ter funcionado bem ou mal não fará diferença alguma e o Estado será responsável pelos danos causados à vítima.

Salientamos que a justificativa desta teoria reside no argumento de que o risco de dano é inerente à atuação do Estado. Portanto, uma vez causado o dano, o Estado responderá objetivamente, isto é, independentemente de culpa do agente público.

Meirelles (1994, p.552) classifica a teoria do risco em duas modalidades: a do risco administrativo, que admite as excludentes de responsabilidade do Estado e a do risco integral, que não admite as excludentes de responsabilidade. Porém, esta divisão não é aceita pela doutrina dominante, que, ao considerar as expressões risco integral e risco administrativo como sinônimos (Di Pietro, 2005, p. 565), compreende a teoria do risco como uma só e admite as excludentes de responsabilidade do Estado: força maior; culpa da vítima; culpa de terceiros; e estado de necessidade, pois esses fatores rompem o nexo de causalidade (Cahali, 1995, p. 40).

Consideramos conveniente apontar que as excludentes de ilicitude são situações que permitem que o Estado negue o nexo de causalidade e, portanto, afaste a responsabilidade pelo dano. Ora, o Direito brasileiro adota a teoria da responsabilidade estatal objetiva, bastando, destarte, o dano e o nexo de causalidade para a configuração da responsabilidade do Estado e, uma vez afastado o nexo de causalidade, não haverá a possibilidade de indenização. 
Di Pietro (2005, p. 568) assevera que, nas hipóteses de força maior e de culpa da vítima, o nexo de causalidade será rompido, pois essas hipóteses se constituem causas excludentes da responsabilidade.

As hipóteses de força maior normalmente são confundidas com as de caso fortuito. Porém, estes institutos, apesar de guardarem semelhanças, possuem conceitos distintos. A força maior é um acontecimento imprevisível, inevitável e contrário à vontade das partes (como um furacão, um raio, um terremoto), já o caso fortuito é um acontecimento decorrente de um ato humano.

A força maior deve ser entendida como ato da natureza. Entretanto, a existência de força maior não pode ser alegada em hipóteses onde o dano seja oriundo da omissão do serviço público ${ }^{1}$, quando, segundo os ensinamentos de Bandeira de Mello (2004, p. 906-908) e Di Pietro (2005, p. 568), a responsabilidade do Estado será subjetiva.

A culpa da vítima ocorre quando esta se coloca na posição de sofrer o dano e efetivamente o sofre, como o caso do pedestre suicida que provoca seu próprio atropelamento, hipótese que afastará o nexo de causalidade. Entretanto, caso a culpa seja concorrente, o nexo de causalidade não poderá ser afastado integralmente e a responsabilidade do Estado será repartida com a vítima.

\section{$\checkmark$ A Responsabilidade do Estado no Atual Ordenamento Jurídico Brasileiro}

Enquanto na teoria da responsabilidade subjetiva a culpa (ao lado do dano e do nexo de causalidade entre o fato e o dano) é um pressuposto essencial à existência da obrigação de reparar o dano, na teoria da responsabilidade objetiva a culpa é presumida, ou seja, a existência da obrigação de reparar o dano exige apenas a existência do dano e do nexo de causalidade entre o fato e o dano, não havendo, como na responsabilidade subjetiva, a necessidade de comprovar-se a culpa.

O art. 15 do Código Civil de 1916, que adotou a teoria da responsabilidade civil subjetiva do Estado, disciplinava, in verbis:

As pessoas jurídicas de direito público são civilmente responsáveis por atos de seus representantes que nessa qualidade causem danos a terceiros, procedendo do modo contrário ao direito ou faltando a dever prescrito por lei, salvo direito regressivo contra os causadores do dano.

Porém, a Constituição vigente, em seu art. $37, \S 6^{\circ}$, adotou a teoria objetiva, sob a modalidade do risco, no que tange a responsabilidade civil do Estado, ao preceituar o seguinte:

\footnotetext{
1 "Não se pode, entretanto, cogitar da existência de força maior quando, por exemplo, ocorram inundações na cidade, previsíveis e que demandariam obras de infra-estrutura não realizadas" (Figueiredo, 2004, p.289-290).
} 
As pessoas jurídicas de direito público e as de direito privado prestadoras de serviços públicos responderão pelos danos que seus agentes, nessa qualidade, causarem a terceiros, assegurado o direito de regresso contra o responsável nos casos de dolo ou culpa.

Em consonância com a Constituição Federal, o Código Civil de 2002, em seu art. 43, passou a determinar que:

As pessoas jurídicas de direito público interno são civilmente responsáveis por atos de seus agentes que nessa qualidade causem danos a terceiros, ressalvado direito regressivo contra os causadores do dano, se houver, por parte destes, culpa ou dolo.

Portanto, para que o Estado tenha o dever de indenizar, não se exige o comportamento culposo do agente público, bastando que exista o dano e que este tenha sido causado em virtude da ação estatal. ${ }^{2}$

Após esta exposição acerca da teoria que rege a responsabilidade civil do Estado, passemos à analise de importantes elementos que configuram ou afastam o dever estatal de indenizar.

\subsection{Danos IndenizÁveis}

Dano, segundo o conceito clássico, é uma diminuição ou subtração do patrimônio de um indivíduo. Porém, tal conceito se encontra ultrapassado, pois hodiernamente se entende que o conceito de dano (em sentido amplo) abrange a lesão de qualquer bem jurídico, englobando-se, portanto, além do dano de natureza patrimonial, o dano de natureza moral (Gonçalves, 2005, p. 545-548).

O dever de indenizar, na linha da teoria risco-proveito (Mello, 2004, p. 906-908), tanto pode surgir diante de atos lícitos, quanto de atos ilícitos. Na primeira hipótese, para que surja o dever estatal de indenizar, o dano deverá ser certo, anormal, e especial. Já na segunda, basta que o dano seja certo e que tenham atingido situações jurídicas constituídas.

\subsection{Ação Regressiva e Denunciação da Lide}

Uma vez cumprido o dever estatal de indenizar, ou seja, tendo o Estado reparado integralmente o dano, através da restauração do statu quo ante, ou compensado o dano, posto que, em determinadas hipóteses não será possível a restauração do estado anterior ao dano, o Estado deverá interpor ação regressiva ${ }^{3}$, que é o exercício do direito de regresso previsto tanto pela Constituição Federal,

\footnotetext{
2 "A responsabilidade civil das pessoas de Direito público não depende de prova de culpa, exigindo apenas a realidade do prejuízo injusto" RTJ, 55:516 (Apud Gonçalves, 2005, p. 173).

${ }^{3}$ A lei n ${ }^{\circ} 8.112 / 90$, art. 122 , $\S 2^{\circ}$ disciplina, in verbis: "Tratando-se de dano causado a terceiros, responderá o servidor perante a Fazenda Pública, em ação regressiva".
} 
em seu $\S 6^{\circ}$, art. 37, quanto pelo Código Civil brasileiro, em seu art. 43, segundo o qual o Estado, que indenizou a vítima do dano causado por seu agente, pode requerer a este o ressarcimento das importâncias pagas por aquele.

O exercício do direito de regresso é indisponível, ou seja, acionar o agente público causador do dano, quando este incorrer em dolo ou culpa, é dever do Estado e não mera faculdade. Porém, o Estado somente interporá ação regressiva contra seu agente quando forem atendidas as seguintes condições: 1 ) ser ele (o Estado) condenado a indenizar a vítima do dano; 2) ser passível de comprovação a culpa do agente no evento danoso.

Salientamos que, segundo o $\S 3^{\circ}$ do art. 122 da lei $n^{\circ}$ 8.112/90 (Estatuto dos servidores públicos civis da União), a ação regressiva transmite-se aos herdeiros e sucessores do servidor culpado, podendo ser instaurada mesmo após cessação do exercício no cargo ou função, por disponibilidade, aposentadoria, exoneração ou demissão, já que esta modalidade de ação é uma forma de ressarcir o erário.

Este instrumento, apesar de sua obrigatoriedade e conveniência, não é largamente utilizado, pois muitas vezes o Estado opta por utilizar a via da denunciação da lide.

Dallari (1990, p 139) assevera que é possível denunciar a lide ao funcionário, pois o inciso III do art. 70 do Código de Processo Civil prescreve que "a denunciação da lide é obrigatória [...] àquele que estiver obrigado, pela lei ou pelo contrato, a indenizar, em ação regressiva”.

Os defensores da denunciação da lide, em casos de responsabilidade civil do Estado, fundamentam-se no princípio da economia processual, porém tal justificativa é incompatível com o escopo do princípio consagrado no $\S 6^{\circ}$ do art. 37 da $\mathrm{CF} / 88$, que é o de tornar a reparação do dano célere, efetiva e livre de qualquer forma de perquirição de culpa. Com a imposição da denunciação da lide, pensamos que um aumento de obstáculos ao lesado é provocado, vez que será instaurada, no bojo da lide, outra lide.

\section{\ Responsabilidade Civil do Estado por Atos Jurisdicionais}

Função, no dizer de Rocha (2003, p. 75-76), “é uma atividade desenvolvida para atender às necessidades de outrem”, por conseguinte, para alcançar os fins que lhes são inerentes, o Estado deve desenvolver certas atividades que visem a suprir as necessidades dos administrados.

A função estatal é tripartida em executiva, legislativa e jurisdicional, e cada uma dessas funções é atribuída a um órgão criado pelo Estado exatamente para exercê-la

\footnotetext{
${ }^{4}$ Segundo o sistema de organização e funcionamento do poder estatal de Montesquieu, o Estado, para desempenhar suas funções, pode criar órgãos distintos e autônomos em correspondência com a diversidade de funções que deve desenvolver (apud Rocha, 2003, p. 76-78).
} 
A função jurisdicional consiste na aplicação do Direito e foi atribuída ao poder Judiciário, que a exercita através de seus agentes, os juízes, que, em regra ${ }^{5}$, solucionarão os conflitos de interesses levados à apreciação do referido poder.

Estabelecida a relação processual, o juiz pronunciará a vontade do Estado através de despachos de mero expediente, decisões interlocutórias e sentenças, atos que podem vir a causar danos aos sujeitos da relação processual.

Anteriormente estudamos que, em nosso ordenamento jurídico, o Estado poderia ser responsabilizado objetivamente pelos danos causados pelos atos omissivos ou comissivos, lícitos ou ilícitos de seus agentes. Porém, durante muito tempo se entendeu que os atos executados por juízes não poderiam ensejar a responsabilidade do Estado, predominando, numa determinada época, a teoria da irresponsabilidade do Estado por atos judiciais danosos.

Para refutar a teoria da responsabilidade, os pregadores da teoria da irresponsabilidade defendiam os seguintes argumentos:

a) O Judiciário é soberano, tanto que seus atos (despachos, decisões interlocutórias e sentenças) expressam a soberania nacional, não podendo, portanto, o referido poder ser responsabilizado pelos seus atos, pois, de forma semelhante ao rei no estado absolutista, o poder Judiciário está acima da lei;

b) o temor de causar dano, originado da responsabilização do Estado por atos judiciais, poderia restringir a independência dos magistrados no exercício de suas funções;

c) os juízes não podem ser classificados como agentes do Estado;

d) atribuir responsabilidade ao Estado por ato judicial eivado de erro pode agredir a regra da imutabilidade da coisa julgada.

Em contrapartida, para ilidir os argumentos acima mencionados, os partidários da teoria afirmativa da responsabilidade do Estado dizem o seguinte:

a) O Judiciário não é soberano, pois, assim como os demais poderes, devem obediência à Constituição e à Lei. A soberania é exercida exclusivamente pelo Estado, tanto que não há nenhum poder superior ao dele;

b) a independência do juiz não corresponde à falsa idéia de infalibilidade e intangibilidade proposta pelos defensores da teoria da irresponsabilidade, portanto, responsabilizar o Estado não opera a restrição da independência dos juízes, pois, a independência é um predicado conferido a todos os poderes;

c) o magistrado é agente público, ocupante de cargo criado por lei e submisso à regra imposta pelo art. $37, \S 6^{\circ}$ da $\mathrm{CF} / 88$. A doutrina configura magistrado modernamente como agente político e detentor de cargo vitalício;

\footnotetext{
${ }^{5}$ Em hipóteses específicas, o poder Judiciário, além de sua função precípua, exercerá funções administrativas, como as decorrentes do poder hierárquico sobre seus servidores, ou como a jurisdição voluntária, ou mesmo legislativa, no exercício do poder regulamentar (elaboração do regimento interno dos tribunais, por exemplo).
} 
d) o dever de indenizar do Estado não fere a regra da imutabilidade da coisa julgada, pois, ele mesmo irá indenizar o administrado pelo prejuízo sofrido, mas a coisa julgada permanecerá intacta; em outras palavras, a decisão judicial causadora do dano continuará a valer para as partes vinculadas pela mesma, exceto nas hipóteses de rescisão da sentença de mérito, transitada em julgado, previstas pelo art. 485, do Código de Processo Civil.

Conseqüentemente, não há empecilhos em responsabilizar o Estado por atos praticados por uma de suas funções, a judiciária; na realidade, o contrário, isto é, não responsabilizar o Estado pelo erro cometido por seu agente na prática de atos de jurisdição, configuraria denegação de justiça.

Salientamos que, no que tange o assunto em discussão, a doutrina ainda não é pacífica, porém diversos doutrinadores já aceitam a responsabilidade do Estado por atos jurisdicionais ${ }^{6}$.

Em recente oportunidade, o Supremo Tribunal Federal demonstrou que admite a responsabilidade do Estado por atos judiciais ao decidir da seguinte forma:

A autoridade judiciária não tem responsabilidade civil pelos atos jurisdicionais praticados. Os magistrados enquadram-se na espécie agente político, investidos para o exercício de atribuições constitucionais, sendo dotados de plena liberdade funcional no desempenho de suas funções, com prerrogativas próprias e legislação específica. Ação que deveria ter sido ajuizada contra a Fazenda Estadual — responsável eventual pelos alegados danos causados pela autoridade judicial, ao exercer suas atribuições a qual, posteriormente, terá assegurado o direito de regresso contra o magistrado responsável, nas hipóteses de dolo ou culpa. Legitimidade passiva reservada ao Estado. Ausência de responsabilidade concorrente em face dos eventuais prejuízos causados a terceiros pela autoridade julgadora no exercício de suas funções, a teor do art. 37, § $6^{\circ}$, da CF/88 (RE 228.977, Rel. Min. Néri da Silveira, DJ 12/04/02).

A supracitada decisão afirma que a legitimidade passiva, em ações relativas ao assunto da responsabilidade por erro em atos jurisdicionais, é reservada ao Estado, que terá direito de regresso contra o agente causador do dano, quando este tiver incorrido em dolo ou culpa; em outras palavras, a referida decisão confirma a possibilidade de aplicação da teoria da responsabilidade objetiva nos casos de erro nos atos jurisdicionais.

${ }^{6}$ Dentre outros, Lúcia do Valle Figueiredo, Maria Sylvia Zanella Di Pietro, Marcelo Sampaio Siqueira e Carlos Roberto Gonçalves aceitam a responsabilidade do Estado por atos jurisdicionais. 
Por conseguinte, a vítima do dano deverá interpor ação indenizatória contra o Estado, que, mediante constatação do dano e do nexo de causalidade, será obrigado a indenizar, não sendo a verificação de culpa necessária.

Ainda analisando a aludida decisão, é conveniente trazer à baila o fato de o magistrado ter sido declarado parte ilegítima naquela relação jurídica.

O CPC, em seu artigo 133, preceitua que a responsabilidade pessoal do julgador ocorrerá quando o mesmo agir dolosamente ou fraudulentamente no exercício de suas funções, ou quando o juiz recusa, retarda, ou omite, sem justo motivo, providências que deva determinar de ofício ou a requerimento das partes, desde que, cientificado pelo escrivão, não o faça dentro do lapso temporal de dez dias.

Segundo Siqueira (2001, p. 205), o ato emanado pelo juiz poderá acarretar, em linhas gerais, as seguintes conseqüências: a) de natureza penal, quando o magistrado tiver cometido algum ilícito penal; b) de natureza disciplinar, quando o magistrado poderá sofrer sanções funcionais adotadas pela própria magistratura; e c) de natureza patrimonial, quando o juiz responderá diretamente à vítima ou ao Estado em sede de ação regressiva.

A doutrina preceitua que o magistrado somente será responsabilizado pessoalmente nos casos previstos em lei, como o do artigo 133 do CPC, porém, as possibilidades da responsabilidade pessoal do magistrado devem ser ampliadas.

Machado (2004, p.468-470), ao apontar o caminho para a inibição das sanções políticas ${ }^{7}$, diz que, enquanto a autoridade pública não for responsabilizada pelas práticas ilegais, ela continuará a agir de forma arbitrária, porque não está preocupada com a ilegalidade e, mesmo diante da responsabilização da entidade pública, a ilegalidade continua a ser praticada, pois, o instituto consagrado no artigo 37, §6 $6^{\circ}$ da CF/88 não possui eficácia, no primeiro momento, contra o agente, que certamente procrastinará o desfecho da questão e entregará o problema da indenização ao seu sucessor, porém, a partir do momento em que a autoridade sentir-se responsabilizada, pessoalmente, pela conduta ilegal ou abusiva, certamente passará a refletir antes de prosseguir em sua prática.

O instituto da ação regressiva, que poderia inibir a conduta ilegal da autoridade, está falido, pois, uma vez prestado o dever de indenizar, o Estado não tem buscado o ressarcimento do erário junto aos agentes públicos, contrariando a regra da indisponibilidade do instituto da ação regressiva.

O escopo da sugestão que ora apresentamos não é o de permitir que as partes responsabilizem o juiz por quaisquer prejuízos causados pela decisão proferida acertadamente em favor da parte adversária, mas é o de ofertar um instrumento apto a inibir a conduta ilegal da autoridade judiciária.

Sanções políticas são formas inconstitucionais de restringir os direitos do contribuinte que objetivam coagir o mesmo a pagar os tributos (Machado, 2004, p.468). 
Portanto, concluímos que o juiz pode ser responsabilizado pessoalmente pelos seus atos e que, diante da falência do instituto da ação regressiva, e dos prejuízos que a denunciação da lide acarretam ao lesado, este é o melhor meio de inibição de condutas ilegais do juiz.

\section{Considerações Finais}

Mediante o exposto, analisamos a teoria da responsabilidade do Estado e constatamos que, segundo o dito art. $37, \S 6^{\circ}$ da CF/88, esta responsabilidade é objetiva, salvo na hipótese de omissão, e que a responsabilidade dos agentes públicos é subjetiva, e concluímos que o Estado pode responder objetivamente por atos judiciais eivados de ilegalidade ou erro e que a atribuição de responsabilidade pessoal aos juízes é possível.

\section{Y RefERÊNCIAS BibliográfiCAS}

BANDEIRA DE MELLO, Celso Antônio. Curso de Direito Administrativo. 17 ed. São Paulo: Malheiros, 2004.

CAHALI, Yussef Said. Responsabilidade civil do Estado. 2 ed. São Paulo: Malheiros, 1995.

DALLARI, Adílson de Abreu. Regime Constitucional dos Servidores Públicos. 2 ed. São Paulo: RT, 1990.

DI PIETRO, Maria Sylvia Zanella. Direito Administrativo. 18 ed. São Paulo: Atlas, 2005.

FIGUEIREDO, Lúcia Valle. Curso de Direito Administrativo. 7 ed. São Paulo: Malheiros, 2004.

GONÇALVES, Carlos Roberto. Responsabilidade Civil. 9 ed. São Paulo: Saraiva, 2005.

MACHADO, Hugo de Brito. Curso de Direito Tributário. 24. ed. São Paulo: Malheiros, 2004.

MEIRELLES, Hely Lopes. Direito Administrativo Brasileiro. 19 ed. rev. e atual. São Paulo: Malheiros, 1994.

ROCHA, José de Albuquerque. Teoria Geral do Processo. 7 ed. São Paulo: Atlas, 2003.

SIQUEIRA, Marcelo Sampaio. Responsabilidade do Estado: Erro Judicial praticado em ação cível. Belo Horizonte: Mandamentos, 2001. 


\section{STATE RESPONSIBILITY FOR JURISDICTIONAL ERROR}

Abstract: This work examines the controversial matter of the responsibility of the state due to error practiced in the jurisdictional arena. It will be demonstrated the possibility of attribution of objective responsibility to the state and the subjective to the damage's causing agent (judge). The study is based on documentary research, with emphasis on doctrine and jurisprudence.

Keywords: Responsibility. State. Jurisdiction. Error. Judge. 